\title{
The Influence of Students' Interpersonal Nature on Adjustment to Loss and Grief on Kenyan Orphaned Secondary School Students
}

\author{
Judith Anyango Owaa \\ PhD Student, Jaramogi Oginga Odinga University of Science and Technology \\ *Dr. Peter J.O. Aloka \\ Department of Psychology, Jaramogi Oginga Odinga University of Science and Technology, Kenya \\ jairopeteraloka@yahoo.com \\ Dr. Pamela Raburu \\ Head of Department of Psychology, Jaramogi Oginga Odinga University of Science and Technology
}

\author{
Doi:10.5901/mjss.2015.v6n4s1p333
}

\section{Abstract}

The purpose of the study was to determine the influence of students' interpersonal nature on adjustment to Loss and Grief on orphaned Kenyan secondary school students.The study was informed by Erikson's Psychosocial Theory of Human Development. Mixed method research approach was used and with it, concurrent triangulation design was adopted. The target population consisted of 47 schools, 20 focus group discussion students, 10 personal interviews and 1,245 Form 3 orphaned students from public secondary schools in Kisumu Central Sub-County of Kenya. A sample size of 453 students from 15 secondary schools were sampled for the study using stratified random sampling technique. Reliability of the instruments was ascertained through a pilot study of $9 \%$ of the population that did not participate in the final study. Internal consistency was also used to determine the reliability of questionnaires and coefficient values of $r=0.0771$ was reported for the questionnaire. Face validity of the instruments was ascertained by pilot testing the questionnaires and also by seeking expert judgment by university lecturers. Data was collected by use of questionnaires, in-depth interviews and focus group discussions. Quantitative data was analyzed using both descriptive and inferential statistics. Qualitative data was analyzed using thematic framework. Trustworthiness of qualitative data was ensured by analyzing the framework as fronted by Lincoln \&Guba (1985). The study findings revealed that there were significant differences on adjustment to loss and grief on the basis of interpersonal nature. Schools should assign teachers adoptive parenting roles for the orphaned students in school.

Keywords: interpersonal nature; adjustment; Loss and Grief; orphans; secondary school; students.

\section{Introduction}

A duty that adolescents have to perform is to maneuver their lives through developmental progression (Taylor, 2011). Aaron (2005) confirms that adolescents experience catastrophic crises as they trudge through this stage. In its early development as a theory, help.fortroubledteens, (2014) records that; adolescence primarily is a time of internal turmoil and upheaval.In America, belief systems development and transition modes in to adulthood acted as huddles for adolescents (Currie \& Thiele, 2009). Adolescents found it hard to be in sync with societal expectations like dress code and grooming. In Italy, consumption of alcohol and illicit drug use were top of the agenda on issues that affected adolescents socially (Santrock, 2007). While Darwin believed that adolescence was a representation of our human ancestors' shift from being primitive to civilized (Hall, 2006), Freud argued that, the psychological disturbances associated with adolescence were biologically based as quoted in (Hoffnung, 2007) and culturally universal (Corey, 2001a). Berk, (2009) \& Gross (2005) concur that, many adolescents make poor or erratic choices due to the varied factors that govern their progression.

In Africa, media influence and body image have been rated as pertinent to adolescents as seen in (Scharf \& Shulman, 2010).In Kisumu Central Sub-County of Kenya, counselling organizations got concerned at the rate at which adolescents were not able to cope with adjusting to loss and grief as shown by (Okello, 2008). The study by Owaa, (2010) also reported that, $56 \%$ of adolescent orphans that requested for therapy were not able to cope with 
developmental issues and were looking for whom to talk with to be able to process their loss. Kenya Institute of Professional Counsellors (KIPC), recorded that $63 \%$ of truancy in secondary schools could be traced to orphans. Agape Counselling and Training Services (ACTS), noted with concern that in a survey of 60 schools in which they conducted peer counselling training in the then Nyanza province, $74 \%$ of students that saw the need to find therapy were bottled with unprocessed loss and grief (Owaa, 2010). This therefore implies that the orphaned adolescent students have the challenge of adjustment to loss and griefCoupled with the survey by NASCOP (2012), which revealed that new HIV infections are high among married couples at a rate 14-19\%, more adolescents are forced to walk the tight rope of bearing the loss of their loved ones with no one to help them begin the adjustment process to near-normalcy again. Leek, (2011) observed that this can be catastrophic! Moreover, socio-cultural intrigues such as barriers in communication, denial as an ego defense mechanism and limited capacity building amongst societies in Kisumu Central Sub-County, (Okello, 2008; Egan, 2008) were facts on the ground that needed to be addressed.

The study by Owuor \& Mauta, (2011) revealed that socio-cultural and family set ups are wanting in the provision of the much needed therapy, the present study intends to fill the gap by finding out if within the society there are laid down structures and strategies that adolescent adopt to while adjusting to loss and grief. Cremin, (2007) therefore defined adaptation strategies as societal guidelines and steps in the right direction for a member of the community in turmoil which for the present study would mean - adolescent progression crises that may be coupled with adjusting to loss and grief. British Association of Counselling \& Psychotherapy (2009) argued that adaptation strategies and techniques may provide adolescents with cognitive ability to be able to believe in themselves and find solace during turmoil periods that the present study wishes to find out. Gray \& Tindall, (2008) also added that, the already grim situation, midwifed by adolescent progression factors, may be worse for adolescents who have suffered loss, are grieving, unattended and are struggling to adjust.

Therefore, the present study determined the influence of students' interpersonal nature on adjustment to Loss and Grief on orphaned Kenyan secondary school students.

\section{Theoretical Framework and Literature Review}

\subsection{Theoretical Framework}

This study was informed by Erik Erikson's (1968) Psychosocial Theory of Human Development, and Kübler-Ross Cycle model (1969) of loss and grief. According to Erikson, the social set up of an individual had greater influence on him than his primitive impulses (Gross, 2005). Erikson's Psychosocial theory of Human Development was entrenched in his book "Identity: Youth and Crisis (1968)" He believed that as a person grew, his greatest concern, (consciously or otherwise) was Identity. He segmented aperson's life span in to eight paired stages which he called: Basic trust vs. basic mistrust (hope), Autonomy vs. Shame (will), Initiative vs. Guilt (purpose), Industry vs. Inferiority (competence), Identity vs. Role Confusion (fidelity), Intimacy vs. isolation (love), Generativity vs. stagnation (care) and Ego integrity vs. despair (wisdom) (Engler, 2008). The stages that mirrored a person's life span were pegged to favourable outcomes which he termed as 'personality virtues'. In the event that a virtue was missed at a particular stage, Erikson said that a person got in to an Identity Crisis. He therefore built on Freud's ideas and extended it by stressing the psychosocial aspects of development beyond early childhood (Gross, 2005). This was how Erikson's theory became suitable for adolescents who were at the center of the present study. He explored three aspects of identity: the ego identity (self), personal identity (the personal idiosyncrasies that distinguish a person from another and social/cultural identity (the collection of social roles a person might play).

\subsection{Literature Review}

Charach, Yeung, \& Lillie, (2011) said that death of a parent, guardian, sibling or peer can be catastrophic to an adolescent. Tharp-Taylor, Haviland \& D'Amico, (2012) concured that much as loss and grief was processed personally (MedlinePlus, 2012), it also had a significant interpersonal aspect. In the present study, interpersonal nature of adolescents was viewed in terms of extroversion and introversion. In a qualitative study by Lichtentahl \& Cruess, (2010) that aimed at comparing the adjustment of adolescents who experienced death of a parent but managed to talk about it with significant other, with those who experienced parental divorce and were sent to children homes and did not process their loss among students in a Canterbury rescue center. The study sampled 217 adolescents with a gender parity of 98 males and 219 females. The study findings revealed parental death had a uniqueimpact on adolescent as it disturbed perceptions of interpersonal relationships yet being able to talk about their grief made recovery better. The study findings 
revealedthat, the adolescents whose parents did not die but were separated yet were not able to talk about it exhibited more grief tendencies. The study results showed increased isolation and resultant decreased support at a time when relationships with peers, parents, and teachers were deemed critical to adjustment to loss. It also showed that the ones who found it possible to talk were adjusted in their well-being, and were able to develop an identity. The study concluded that loss and grief was well managed through opening up to support. However, the reviewed study used qualitative method for data analysis while the present study filled the literature gap by using both qualitative and quantitative methods.

Similarly, Jenkins, (2007) conducted a study that measured adjustment difficulties on Hopkins Symptom Checklista sensitive case-finder of clinically important depressive states in adolescents and elderly people in primary care. The study used structured interviews of 37 people with a high depressive score and with a low depressive score in HSCL-25, in order to compare the HSCL-25 ratings with the Montgomery-Asberg-Depression Rating Scale (MADRS) as well as with the criteria for major, minor and subsyndromal depression. Results indicated that, the sensitivity for identifying any depression was $94 \%$ and the specificity was $94 \%$ for HSCL-25 was on 12 respondents that hardly shared their views compared to the diagnostic criteria for depressive disorders that cited 25 respondents who were aware that they were depressed but tried to talk about it even by just the mere acknowledgement that they were depressed. The study concluded that HSCL-25 was a sensitive case-finder of depressive disorders but showed useful results in general practice and screening studies of depression in adolescents who acknowledged their state of depression. However, the study that was reviewed measured qualitative adjustment difficulties with a disconnect to specific interpersonal tendencies of adolescents to the persons responsible for their depressive situations or states. The present study therefore, filled the gap by using mixed methods.

Another study by Miesbach, (2013) investigated subscales of somatization, obsessive-compulsive activity, interpersonal sensitivity, depression, and anxiety as interpersonal distinct traits among work force adults in Mississippi Ridge. The study encompassed 59 adults, 37 males and 22 females. The study findings revealed that most accidents at the place of work were experienced by introverts irrespective of whether they were male or female. The study also noted that tendencies of somatization, obsessive-compulsive activity, interpersonal sensitivity, depression, and anxiety as interpersonal distinct traitswere overtly experienced more by introverts than extroverts. Good working relations were enjoyed by extroverts who found it easy to express themselves. Results also indicated feelings of inadequacy and inferiority, difficulties with social competence assessed as participation in activities, working, or getting along with others, as well as school functioning was prevalent for both sexes in equal measure for introverted and not extroverted personalities. The study therefore concluded that introverted personalities experienced more inadequacy and inferiority difficulties with social competence as they participated in activities while working or trying to get along with others. However, the reviewed study was based in Mississippi and involved adults work force. The present study filled that gap by conducting focus group discussions to retrieve personal views on introversion and extroversion among adolescent students' adjustment to loss and grief.

In addition, Cooney (2010) surveyed 112 adolescents in Ohio who were living with relatives after the impact of parental death. The survey captured adolescents aged 13 to 19 that were enrolled and ongoing in integrated schools. The study found a link between lower depression scores and high levels of derived informal social support. The study also found that adolescents who purposed to attend and participate in the informal support forums had a balanced personality coupled with a good relationship with the significant other. However, the reviewed study wasconducted among adolescents in Ohio USA that attended integrated schools. The present study therefore bridged the gap in literature by studying adolescents' interpersonal nature in the process of adjustment to loss and grief in Kenya.

De Kock, (2014) conducted a debriefing survey with 21 affected family members of Khulumani Support Group death squad victims in South Africa that were in the process of dealing with their loss and continuing grief. The family members were interested in knowingfirst-hand information about the circumstances of the killing of their loved ones. The study findings revealed that $73 \%$ of family members felt that getting answers to these questions was very important for family members in the recovery process of ambiguous loss or complicated grief. The study concluded that complicated or sudden grief had greater effect on family members and produced different results depending on a person's interpersonal nature. It also concluded that affected persons got stuck in an emotional no-man's land leading to complicated grief depending on a person's introversion or extroversion nature. The reviewed study was based on South African widows and how they showed their different personalities as they sought to find out the cause of deaths. The present study filled the gap in literature by providing the explicit nature of introversion and extroversion among Kenyan adolescents.

Nyamwange, (2010) conducted a causal comparative design that exploredpersonality relationships between victims who received psychotherapeutic support and those who did not in Kenya. The study used a sample consisting of a total of 627 respondents drawn from 2,040 IDPs or approximately $31 \%$, selected through stratified random sampling 
method from 12 geographical localities across two provinces in seven districts of Kenya that participated in the study.In addition, the study interviewed 20 professionals who intervenedin trauma cases from 10 humanitarian agencies. The findings of the study indicated that in relation to social and personality adjustment, the study found that victims who sought and received psychological support (i.e. 84\%of the respondents) had a better social and personality adjustment than those who did not. Respondents felt much better, made social and personality adjustments and once more felt in control of their lives again. The reviewed study however used causal comparative design with all in the IDP camp and not students in school while the present study used mixed method design.

Abanti, Musoke \& Muiga (2014) conducted a quantitative research on how personality traits influenced usage of health informatics systems in Nyanza Region - Kenya. The study used questionnaire survey technique to collect the data randomly from a sample population of 163 health workers in Level 5 Hospitals in Nyanza, Kenya. This showed that most of health workers in the Nyanza level 5 hospitals were male and was attributed to a number of factors such as need for career progression, need to pursue higher studies, family responsibility and self-motivation. Pressure to adopt the new technology in their day to day operation accounted for $49 \%$ across the sexes while $37 \%$ were not able to cope. $14 \%$ of the respondents were non committal on personality influence. The reviewed study used quantitative method and not mixed method to collect data, while the present study filled the gap in literature by using mixed method for hybrid results.

\section{Research Methodology}

\subsection{Research Design}

The researcher adopted concurrent triangulation model where both quantitative and qualitative data was collected. In this model therefore, both quantitative and qualitative data collected was analyzed at the same time of the research study. The researcher therefore gave equal priority to both components (Murdin, 2009). Ideologically, priority was slotted equally between the two methods, but practically as findings were analyzed priority tilted to qualitative approach (Creswell \& Plano-Clark, 2011).With regards to treating both data, triangulation was ably adopted (Stake, 2010). Triangulation refers to a combination of methodologies in a study of the same phenomenon (Rothbauer, 2008).

\subsection{Study Participants}

Target population for the present study comprised of 1245 form three partially or totally orphaned students in public secondary schools in Kisumu Central Sub-County.Target population for the present study comprised of 1245 form three partially or totally orphaned students in public secondary schools in Kisumu Central Sub-County.A sample size of 453 secondary school students from 15 schools were selected to participate in this study using stratified random sampling technique. The sample size of 453 students for quantitative sample was considered appropriate since according to Bragg, (2011) who noted that one third of a population was an adequate sample, whose information can be deduced for the general population. A sample of 10 partial or total orphaned students were selected from the sampled schools for interviews using purposive sampling technique. According to Lucas (2013), purposive sampling technique is primarily used in qualitative studies was defined as selecting units (e.g., individuals, groups of individuals, institutions) based on specific purposes associated with answering a research study's questions.

\subsection{Research Instruments}

The Interpersonal Questionnaire for students is an instrument that was used for quantitative data collection on adolescents' personality, while interviews were used to collect qualitative data. In depth-interviewing was employed in the present study because it enabled the researcher to understand and interpret social reality through meanings that the respondents attached to their career experiences (Punch, 2010). Hein \& Singer, (2008) noted that adolescence interpersonal nature strongly suggested that affective empathy-perceivers' that are also known as extroverts, have an experience of social target emotions and contributes to empathic accuracy. The others that do not sense perceivers' ability to accurately assess targets' emotions are known as introverts. Using interpersonal nature-rating questionnaire, it was believed that adolescent's trait on progression and adjustment to loss and grief would be achieved. The IQ was self explanatory and student respondents reflected on their inner feelings to be able to fill the questionnaire. The response format was designed in a 5-point Likert scale: Strongly Agree, Agree, Undecided, Disagree and Strongly Disagree.

To ascertain the usability of the instrument, the researcher adopted expert judgment that was lecturers of Jaramogi Oginga Odinga University of Science and Technology from the department of Education psychology for verification and 
feedback during seminar presentations. In the present study the internal consistency of the instruments was obtained by computing Cronbach alpha (a) using SPSS Version 20. Averages of all possible 'split-half' correlation coefficients resulting from different ways of splitting the scale items were computed.The researcher also computed the reliability for multi-item opinion questions. The items were tested using Cronbach alpha and it gave an overall reliability of 0.788 as indicated on Table 3.7. The result was an indication that the present internal consistency which was above the recommended reliability of $0.6 ; a>0.6$ indicated satisfactory internal consistency reliability for the multi item opinion questions. Quantitative data was collected using questionnaires from 345 students while qualitative data was collected using 10 personal interviews. Focus group discussions were conducted with 20 semi and total orphans to collect qualitative data.

\subsection{Data Collection Procedures}

Data collection procedure began after the proposal had been accepted and approved by the university supervisors. An introductory letter was acquired from Board of post graduate studies of Jaramogi Oginga Odinga University. Permission to proceed to the field and collect data was sought from the National Council of Science and Technology. Ethical issues were considered. This included privacy of possible and actual participants, voluntary nature of participation, consent and possible deception of participation and maintenance of confidentiality of data provided. Questionnaires were issued to sampled students while interviews were held with a few of them and the responses tape recorded. Quantitative data was collected using questionnaires from 345 students while qualitative data was collected using 10 personal interviews. Focus group discussions were conducted with 20 semi and total orphans to collect qualitative data.

\subsection{Data Analysis}

Quantitative analyses involved the use of descriptive and inferential statistics. The inferential statistics allowed researcher to present data obtained in statistical format so as to facilitate identification of important information derived from research questions that made data analysis more meaningful. Quantitative data was analyzed by statistical tests such as independent sample tests. In the present study, raw data that was produced from 20 tape recorded views and 10 personal interviews that were transcribed and read over and over so as to check for any incomplete, inconsistent or irrelevant data (Mason, 2010). Transcriptions were analyzed thematically using the process described by Creswell \& Plano-Clark, (2011) in their deliberations.

\section{Findings and Discussion}

The study found out the relationship between students' interpersonal nature and adjustment to loss and grief on orphaned secondary school students in Kisumu Central Sub-County. This objective was achieved, first, by testing the null hypothesis that: 'There is no statistically significant relationship between the students' interpersonal nature and adjustment to loss and grief among orphaned secondary school students' and then, second, the researcher compared how the two extremes of interpersonal nature adjusted to loss and grief. Interpersonal nature which refers to extraversion and introversion, are typically viewed as two differing extremes in personality. Introverted individuals exhibit attitude-type characterised by orientation in life through subjective focus on one's inner psychic activity while extraversion manifests an attitude type characterised by concentration of interest on the external object (Charach et.al, 2011; Tharp-Taylor et.al, 2012). Students' interpersonal nature was believed to have a bearing to the process of adjustment to loss and grief.However the findings of this study revealed that most respondents had both extraverted and introverted sides, with one being more dominant than the other. So adolescents, just like the rest of mankind, could bein any of the two extremes.

To explore the students' interpersonal nature the researcher computed frequency percentages of the responses on ameasuring scale. The instrument used wasa twenty nine-item likert-type of five options. The options of the interpersonal scale which were strongly agree (SA), agree (A), undecided (U), disagree (D) and strongly disagree (SD) were used toassess the respondents' views on various indicators of aspects of manifestations of interpersonal nature. To ascertain whether there were differences on adjustment on the basis of interpersonal nature of adjustment to loss and grief, an independent t-test was carried out. The descriptive statistics were as presented on Table 4.11. 
Table 4.1. Group statistics on interpersonal nature of adjustment

\begin{tabular}{|c|c|c|c|c|c|}
\hline \multicolumn{7}{|c|}{ Group Statistics } \\
\hline & Temperament & $\mathbf{N}$ & Mean & STD. Deviation & STD. Error Mean \\
\hline \multirow{2}{*}{ AdjustmenT } & Introverts & 27 & .0333 & .38531 & .07415 \\
\cline { 2 - 6 } & Extroverts & 113 & .1796 & .31768 & .02988 \\
\hline
\end{tabular}

The results showed that the mean score for extroverts was slightly $(M=0.1796, S . E=.02988)$ higher than that for the introverts $(M=0.0333, S . E=.07415)$. Therefore there was a difference between extroverts and introverts of orphaned adolescents in the process of adjustment to loss and grief. Thus it was suffice to conclude that personality influenced the rate of adjustment to loss and grief. The mean score for adjustment to loss and grief was also calculated and a t-test was conducted to establish whether there was a statistically significant difference between students with the two extremes of interpersonal nature. However, since the mean score for the extroverts was higher, it became a strong pointer to the fact that extroverts adjusted faster than the introverts. Lichtentahl \& Cruess (2010) and Abanti et.al, (2014) were in agreement that adjustment to loss and grief was a personal issue and that it varied from one person to another depending on their personality. In concordance with the present study, existing literature showed that introversion and extroversion are the major personality types of adolescents.

To determine whether there were statistically significant differences in adjustment to loss and grief on the basis of interpersonal nature, a t-test was carried out and the results were presented on Table 4.12.

Table 4.2. T-test SSPS output on interpersonal nature

\begin{tabular}{|c|c|c|c|c|c|c|c|c|c|c|}
\hline \multicolumn{11}{|c|}{ Independent Samples Test } \\
\hline & & \multicolumn{2}{|c|}{$\begin{array}{c}\text { Levene's Test For Equality } \\
\text { Of Variances }\end{array}$} & \multicolumn{7}{|c|}{ T-Test For Equality Of Means } \\
\hline & & & & & & & & & $\begin{array}{r}95 \% \mathrm{C} \\
\mathrm{DE}\end{array}$ & $\begin{array}{l}\text { C.IOF } \\
\text { EF. }\end{array}$ \\
\hline & & $\mathrm{F}$ & SIG. & $T$ & DF & Sig. (2-tailed) & Mean Difference & Std. Error Diff. & Lower & Upper \\
\hline \multirow{2}{*}{ Adjusting } & $\begin{array}{l}\text { Equal Variances } \\
\text { Assumed }\end{array}$ & 1.685 & .196 & -2.061 & 138 & .041 & -.14631 & .07101 & \begin{tabular}{|c|}
- \\
28671 \\
\end{tabular} & $\begin{array}{c}- \\
.00591\end{array}$ \\
\hline & $\begin{array}{l}\text { Equal Variances Not } \\
\text { Assumed }\end{array}$ & & & -1.830 & 34.918 & .076 & -.14631 & .07995 & $\begin{array}{c}- \\
30863 \\
\end{array}$ & .01600 \\
\hline
\end{tabular}

When equal variance was assumed, then the difference was statistically significant at $a=0.05$ level of significance ( $p$ value for the t-test was 0.041), as shown in the SPSS output shown on Table 4.12. $(P=0.041<0.05)$ as means of adjustment to loss and grief. According to the statements on personal differences in adjustment to loss and grief, the higher mean scores indicated faster adjustment rates. Therefore, from quantitative findings of the present study, we can conclude that orphaned students in Kisumu Central Sub-County's recovery from loss and grief differed depending on their interpersonal nature. Extroverted individuals seemed to adjust from loss and grief faster than their counterparts who are introverted in nature. Lichtentahl \& Cruess, (2010) agreed that introverted adolescents whose parents divorced took a longer time to adjust to their loss. Austin, (2005) also agreed that extroverted adolescents measured positively on the adolescents' response list on grief. Moreover, Carlo et al, (2012) reported that introverts were slow in adjustment to loss and grief while extroverts showed faster rates of adjustment to loss and grief.

Qualitative findings on the relationship between interpersonal nature and adjustment to loss and grief were presented as narrated by focus group discussion respondents and personal interviews.

Expressions from respondents revealed that adolescents that adjusted to loss and grief were either introverts or extroverts. This largely depended on the circumstances before and after loss. Also the events in the process of adjustment to loss and grief played a role in adolescents' interpersonal nature, hence the importance of ascertaining the relationship between interpersonal nature and adjustment to loss and grief.

From the findings of the study, extroverts exhibited adjustment methods such as socio emotional therapy, peer support, talk therapy and seeking companionship. Socio emotional therapy refers to an act of consciously fostering a talk relationship with an individual with an aim of sharing that which makes you irrational so that one can be rational once more and function normally (Knudson-Martin, Wells \& Samman, 2015). The present study respondents confirmed that extroverts are communicators. They yearn for whom to talk with to be able to adjust to loss and grief. A respondent who was born out of wedlock got to know of his state in unfamiliar circumstances. At a family gathering, he got to know that the man he adored was his foster father and not his real father. Immediately, he started asking himself questions as to 
where his real father was and what could have happened. Being an extrovert, he tried talking at home and he ended up with threats. He did not stop there but sought a listening ear from a peer in school. Through his friend in school, he made inroads so that he could work through his loss that had been complicated by threats and ultimatums at home as he narrated;

\section{...I am talking to a friend to help me so that I can meet my real dad...[Fortune]}

The respondent found therapy in two important places; he talked to a peer about his crisis and physically, he endavoured to make plans on how to find his biological father. This process was therapeutic and an onset into adjustment to loss and grief. The fact that he had found someone who was ready to listen to him was already good enough and a sign that he was seeking for help. The present study noted that being an extrovert worked for him as he sought for help. Genga, (2012) also reported on celebration of healing through grieving. He concurred with the present study that shared grief yields healing, a concept that Egan, (2005) also noted that when persons adjusting to loss begin to talk, it signals the onset of healing.

Other respondents sought peer support. Peer support refers to holistic communication with a peer that aims at directly enabling the process of adjustment to be initiated. Support mostly comes with knowledge or experience on what might be stressing the peer and avid exhibits that help can be achieved through trust (Grbac, 2008). Both respondents found talk therapy in their friends and peers at school who instead of judging or talking in hush tones, decided to embrace them the way they were. Their friends allowed them to talk with them anytime they felt disturbed by their loss. An adolescent's loss of womanhood to hysterectomy made her open up to her peers as she narrated;

...my friends at school have been my only consolation, there I can talk, laugh and share. In fact, they are the few who know the real story and they are ready to walk with me and not to condemn me... with them I cry when the pain is too much and I afford to smile when it is bearable...they have walked the rough road with me...[Graceful]

The participant found self through peers at school, where she could share her aches without inhibitions. The respondent's friends allowed her to see beyond her predicament much as the pain was still there. Santrock, (2014) noted that when adolescents are judged by adults, they plough back to peers and confide in them for help especially if they are extroverts thereby building on the 'in-group and out-group' concept of adolescents. Greene, (2014) also agreed that adolescents trusted their friends more than adults because their friends allowed them to cry when things were tough without judgmental perceptions.

Some extroverts used the Talk therapy which is active listening and speaking to a person who needs healing from a therapeutic situation (Sturges, 2012). The strategy makes use of therapist self-disclosure and self-involving statements to allow the respondent to regain wholeness in the process of communication. Gubrium \& Holstein, (2009) also noted that an analysis of one's own statements takes place during talk therapy and may allow a client to come to terms with reality. An adolescent respondent narrated how talking to a peer at school made her feel much better when every other avenue of adjustment to loss and grief had been blocked by societal constraints and she narrated;

...I found solace in a friend at school who had lost a brother to drowning in the lake and the body had not been found to today. He is the only one who understands my pain, he genuinely grieves with me...[Adorable]

The death of the respondent's only brother devastated him. The respondent's pain was managed when he talked to his friend in school, where he discovered that there were other adolescents that adjusted to loss and grief in the presence of progression factors. Forsman, et. al, (2012) had earlier mentioned that extroversion allowed adolescents to open up to the person who was ready to listen to them. Extroversion was a fact that Charmaz, (2006) agreed to when he said that sharing was an investment that adolescents had discovered in the process of adjustment to loss and grief. Leek, (2011) also agreed that extroverts seek help without feeling intimidated by peers. Cheng \& Lo, (2010) argued that parenting and an adolescent's welfare were able to break or make an adolescent. Chew, (2008) also agreed that extroversion made individuals see life as worth living while introversion made individuals lose hope of making it in life.

Some extroverts also sought companionship. Companionship is the art of consciously or unconsciously maintaining a mutual understanding and knowledge that one has someone that can be dependable in the essence of human socialism (Chew, 2008). Extroverts are found in the respondents that yearned for companionship. Parental lifestyle became a respondent's loss that caused him to grieve where the male adolescent had an alcoholic father. He usually arrived home when the son was already asleep and the son left for school when the father was still asleep. The respondent was very proud of his father, so much so that he was forever wishful that one day they would be able to talk 
with him as father and son, not as aliens like it was now, thanks to alcoholism. He shared his fears with his friend in school as he narrated;

\begin{abstract}
...my friend in school is orphaned; she gave me a rude shock when I narrated my story. She said that even the "handonly dad' was better than none. She thought I was better off, as in I had a dad... which she missed completely. She gave me hope to keep trying...one day I may be lucky to get the forum I wanted with dad....quietly I keep hoping that one day I get a forum to tell dad how I miss his personal touch...his association is a big missing link in my life as a growing future father...[Restored]
\end{abstract}

The extroverted respondent sought therapy in his companion in school where he laid bare his fears about his father. He also had a longing for companionship with his father which he had missed for a long time much as they lived in the same house. The respondent seemed to have found a reprieve in his school companion who made the respondent to look at his grieve agent from a different perspective that was full of inspiration. Ciacco, (2008) agreed that an extroverted adolescent maneuvered the loss and grief journey to success more than introverts. Santrock \& Mitterer, (2006) also concurred that the life span of an introverted individual was solitary, issue laden and with difficult questions that may have no answers while extroverted individual was integrated, self propelled and willing to share.

On the other hand, it was also reported that there were introverted students who used various ways to adjust to loss and grief. The themes reported were: being solitary, engaging in self talk, and keeping silent. Being solitary is the act of abiding by one's own company and exuding confidence in it irrespective of other sociable beings around one (Forsman, Manzano, Karabanov, Madison \&Ullén, 2012). Solitary individuals exhibit attitude-type that is characterised by a subjective focus on one's inner psychic activity as was noted by (Charach et.al, 2011; Tharp-Taylor et.al, 2012). A female respondent introduced the study to an introvert's big inner world. She narrated how she decided to keep quiet as she was not able to explain her predicament to anyone. As an introvert, she found it hard even to share with significant other. The study respondent did not find ease in opening up even to her own mother as she narrated;

\title{
...I keep to myself ...[Dependable]
}

The respondent's portray a sharp and decisive reflection which showed that she was solitary and an introvert who trusted no one with her adjustment to loss and grief. The respondent preferred to keep quiet to the world but self talk. Miesbach, (2013) agreed that shutting out the whole world from a griever's perceived world meant peace and tranquility on issues the respondent was not ready to give away. Hien \& Singer, (2008) also noted that introverted adolescents do not talk about their issues as they adjusted to loss and grief but opted to keep quiet and hope things would get better by the days. Adolescents may suppress their feelings and thought if they were introverts as was also alluded to by Gathara, (2014) and that was what the respondent did as a means to adjust to loss and grief.

Others kept silent as a coping mechanism. Keeping silent refers to choosing not to talk or respond where one is expected to talk or respond to issues raised or just to let others know how one feels in relation to particular issues (Pelt, 2005).

Silence was identified as another strategy for adjustment to loss and grief for this introvert respondent who narrated to himself how to get even. Silence described what an introvert may decide to opt for in adjustment to loss and grief. A female respondent found herself in a threefold nature of grief. Like other respondents, her father died and she lost her lifestyle too. She was also grappling with the knowledge that her mother (who was able) did not help her father recover his business and so he got sick and died. The respondent was not able to share what she felt with her mother. She was quiet to display obedience, respect and family synergy. Yet anger was welling inside her. She battled with mental processes of an ongoing revenge that she projected on her mother as was explained in the excerpt;

\footnotetext{
....at least she would have saved dad for my sake if she really loved me. I don't talk to her lest she thinks I don't respect her. Now I am on a revenge path, I am in a relationship with her driver who has been her companion since dad died...[Prosperous]
}

The respondent was hurting silently. She told herself what to do and executed her plan silently. She depended heavily on internal reflections, a characteristic of an introvert. Forster, (2010) agreed that introversion as a personality type exhibited peculiar calm on the outside yet their inside was a beehive of activity. Nyamwange, (2010) added that introverts suffered trauma with no certain visible signs, yet by the time they show visible signs, the crisis could be way out of human proportions. 


\section{Concluding Remarks}

The findings revealed two major aspects of interpersonal nature as extroversion and introversion. The descriptive statistic findings revealed that the orphaned respondents in Kisumu Central Sub-County had more extroverts than introverts in secondary schools that were in the process of adjustment to loss and grief. Inferential statistics showed that the mean score for extroverts was slightly higher than that of introverts. The study concluded that personality influenced adjustment to loss and grief. Quantitative findings reported that extroverts adopted ways such as enjoying talking with others, joining and forming lasting relationships and enjoy stimulating environments to adapt to loss and grief while the introverts adopted ways such as being quiet, mysterious, aloof or calm but thought before they responded or spoke. Qualitative findings reported that extroverts adjusted to loss and grief by socio emotional therapy, peer support, talk therapy and seeking companionship while introverts adjusted to loss and grief through being solitary, engaging in self talk, seeking revenge, keeping silent and sublimation. This implies that personality determines adjustment mechanisms among adolescent students to loss and grief.

Based on the findings of the study there are various implications: First, Schools should strengthen peer counselling among students in their respective schools. This is because the study found out that most orphaned students sought peer support from fellow students. Secondly, schools should assign teachers adoptive parenting roles for the orphaned students in school. This is because some of the orphaned students are introverts and may not find it easy to approach teachers for help, but may be reached by foster parents who may be of help in offering therapy.

\section{References}

Aaron, F. \& Aaron, B. M. (2005).Psychology's Progress and the Psychologist's Personal Experience. London: Routledge.

Abanti, C., Musoke, M. \& Muiga, G. (2014). Personality Traits Influence on Usage of Health Informatics System: Kenya case. International Journal of Scientific and Research Publications, Vol. 4, (3) :2756-2764

Asatsa, S. \& Gichuho, M. C. (2014). An investigation in to the Batsotso Mourning Rituals in Kakamega County, Kenya. International Journal of Science and Research (IJSR) Vol.3 (9):794-79

Austin, S. R. (2005). The Loss Response List: A Tool for Measuring Adolescent Grief Responses. Death Studies. Vol. 15 (1), 10-28

Berk, L. E. (2009). Child Development. (8th ed). United States of America: Pearson Education, Inc.

Bragg, S. M. (2011). Wiley GAAS 2012: Interpretation and Application of Generally Accepted Accounting principles. Canada: Wiley Publishers.

Carlo G., Mestre M. V., McGinley M. M., Samper P., Tur A. \& Sandman D. (2012). The interplay of emotional instability, empathy, and coping on prosocial and aggressive behaviors. Personality and Individual Differences53 (5): 675-680.

Charach, A. E., Yeung, T. C. \& Lillie, E. (2011). Childhood attention-deficit/hyperactivity disorder and social disorders: comparative metaanalyses; Journal of the American Academy of Child and Adolescent Psychiatry, Vol. 50, (1), 9-21.

Charach, A. E., Yeung, T. C. \& Lillie, E. (2011). Childhood attention-deficithyperactivity disorder and social disorders: comparative metaanalyses; Journal of the American Academy of Child and Adolescent Psychiatry, Vol. 50, (1), 9-21.

Charmaz, K. (2006). Constructing a Wounded Adolescent Theory. A practical Guide Through Loss and Grief. London: Sage.

Cheng, T. C. \& Lo, C. C. (2010). The roles of parenting and child welfare services in adaptation therapy for adolescents. Children and Youth Services Review, Vol. 32,(1), pp. 38-43.

Chew, K. (2008). The Adolescence-Factor. http://www.blisstree.com/2008/09/27/mental-health-well-being/the-adolescence-factor/\#ixzz2 JUz5Mbal

Ciacco, J. A. (2008). The Colors of Grief: Understanding a Child's Journey Through Loss from Birth to Adulthood. London: Jessica Kingsley Publishers.

Cooney, E. (2010). "Puberty gap: Obesity splits boys, girls. Adolescent males at top of the BMI chart may be delayed". Retrieved from http://www.msnbc.com/id/35332881/ns/health-kids_and_parenting/ on 2013-05-22

Corey, G. (2001a). Case Approach to Counselling and Psychotherapy (5th Ed.) Pacific Groove: Brooks Cole.

Creswell, J. W. \& Plano-Clark, V. L. (2011). Designing and Conducting Mixed Methods Research (2nd ed.). Thousand Oaks, CA: Sage Publications.

Currie, J. \& Thiele, B. (2009). 'Globalization and Adolescence: Work and Culture in Societies'. In: A. Brooks, and A. Mackinnon, (Eds.): SRHE, Open University.

De Kock, E. (2014). Ambiguous Loss and Complicated Grief: The Plight of Families of Victims of Enforced Disappearances. Retrieved from http//www.ddlive.co.za/opinion on 13 th February, 2014.

Egan, G. (2008). The Skilled Helper - A Problem-Management and Opportunity Development Approach to Helping (7th Ed.) Boston: Brooks Cole.

Egan, G. (2008). The Skilled Helper - A Problem-Management and Opportunity Development Approach to Helping (7th Ed.) Boston: Brooks Cole.

Engler, (2008). Personality Theories: An Introduction. Cengage Learning. p. 151.ISBN 978-0-547-14834-2

Erikson, E. H. (1968). Identity: Youth and Crisis (2nd Ed.) New York: Norton Print. 
Forsman, L. J., de Manzano, Ö., Karabanov, A., Madison, G., \& Ullén, F. (2012). Differences in regional brain volume related to the extraversion and introversion dimension: A voxel based morphometry study. Neuroscience research, 72(1), 59-67

Forster, N. (2010). A Case Study of Adolescents and their Grief Patterns - a UK University. Personality Development International, Vol.6, 28-38.

Freeman, S. J. (2005). Grief \& Loss: Understanding the journey. Belmont, Calif.: Thomson Brooks/Cole.

Furlong, A. (2013). Youth Studies. New York, NY: Routledge.

Gathara, P. (2014). Why does the loss of some lives merit more grieving than the loss of others? Retrieved from http//www.islamicdaily news.com/losts-lives-merit-merit-grieving on 13th November, 2014.

Genga, S. (2012). Healing through Grieving. Retrieved from http://www.standardmedia.co.ke/?articleID=2000070353\&story_title=KenyaHealing-through-grieving on November, $3^{\text {rd }} 2014$.

Grbac, S. (2008). How to implement a 'Peer Support' program in a P-6 School,"Scotch College Junior School, Melbourne Australia. International Boys' Schools Coalition 15th Annual Conference, Toronto, Canada.

Gross, R. (2005). Psychology: The Science of Mind and Behaviour. (5 ${ }^{\text {th }}$ Ed). London: Green Gate Publishing Service.

Gubrium, J. F. \& J. A. Holstein (2009). Analyzing Narrative Reality. Thousand Oaks, CA: Sage.

Gwendolyn, M. (2012). High School Teachers' Perspectives of Student Grief. New York: Oxford University Press.

Hall, V. (2006). Walking on the Ceiling: A study of Adolescent's Management of Crisis in Education. London: Paul Chapman.

Hien, G. \& Singer, T. (2008). The Interpersonal Nature of Empathic Accuracy. Journal of Psychology Science Vol. 19(4) 399 404 . doi: 10.1111/j.1467-9280.2008.02099.x.

http://help.fortroubledteens.com/the-danger-of-treating-teens-like-children.html The danger of treating teens like children. (Retrieved on Friday, $21^{\text {th }}$ February, 2014

Jenkins R. R. (2007). The Epidemiology of Adolescent Health Problems. In: Kliegman R. M. , Behrman R. E., Jenson H. B \& Stanton B. F., eds. Nelson Textbook of Pediatrics. 18th Ed. Philadelphia, Pa: Saunders Elsevier; chap 110.

Knudson-Martin, C., Wells, M. A. \& Samman, S. K. (2015). Socio-Emotional Relationship Therapy :Bridging Emotion, Soceital Context and Couple Interraction. Journal of Personality and Social Psychology. Vol. 15(153) ; 9-13.

Kübler-Ross, E. (2005) On Grief and Grieving: Finding the Meaning of Grief through the Five Stages of Loss. Simon \& Schuster Ltd, ISBN 0-7432-6344-8

Leek, O. L. (2011). "School-based Support Groups for Traumatized Students". School Psychology International. Vol. 32 (2), $163-178$.

Lichtentahl, W. G.; Cruess, D.G. (2010)."Effects of Directed Written disclosure on Grief and Distress symptoms among bereaved individuals". Death Studies; Vol. 34 (6), 475-499.

Lucas, S. R. (2013). "Beyond the Existence Proof: Ontological Conditions, Epistemological Implications, and In-Depth Interview Research.", Quality \& Quantity. Vol 19 (7) 432-439. doi:10.1007/s11135-012-9775-3.

Mason, M. (2010). Sample Size and Saturation in PhD Studies Using Qualitative Interviews. Forum Qualitative Sozial for Schung 1 Forum: Qualitative Social Research, Vol. 11 (3), Art. Retrieved from http://www.nbn-resolving.de/urn:nbn:de:0114-fqs100387 on March 23rd, 2014 ,

MedlinePlus, (2012). Bullying: Retrieved from http://www.nlm.nih.gov/medlineplus/bullying.html.on 29th March, 2014

Miesbach, D. (2013). From Grief to Joy. Retrieved from http://www.opentohope.com/from.grief.to.joy/ on March, $21^{\text {st }} 2014$.

Ministry of Education (2009).Training Module for Guidance and Counselling Heads of Departments in Secondary Schools Nairobi: Elimu Publishers.

Muchai L., Ngari S. \& Mumiukha C. (2014). The Influence of Perceived Post Election Violence on Emotional Well Being among Secondary School Students in Nakuru County, Kenya. International Journal of Innovative Research and Development Vol.3 (3) 126-135.

Murdin, P. (2009). Full Meridian of Glory: Perilous Adventures in the Competition to Measure the Earth. Journal Springer. Vol.1 114-118. ISBN 978-0-387-75533-5

National AIDS \& STI Control Programme (2014). Emerging Trends of HIV \& AIDS Infection and Risk Reduction in Kisumu Region. A Case Study of Rarieda District. 197-201.

Nyamwange, C. (2010). Enhancing Social and Personality adjustment for Trauma Victims: A case of Kenya's post election violence-Loss of connection and anxiety. Retrieved from http//www.kapc.or.ke/callennyamwange/downloads on $27^{\text {th }}$ January, 2015

Okello, L. N. (2008). A Study of Adolescent Development Problems Among Girls in Secondary Schools. A case Study of Siaya and Kisumu Districts. Unpublished Master of Education Thesis: Kenyatta University.

Owaa, J. (2010). Impact of Peer Counselling on Student Discipline in Public Secondary Schools of Kisumu Municipality. Unpublished Master of Education Thesis: Maseno University.

Pelt, N. V. (2005). Heart to Heart-The Art of Communication. (11 th Ed.), Houghton: Editorial Sufeliz.

Punch, F.K. (2010). Introduction to Social Research: Quantitative and Qualitative Approaches. (2nd Edition). New Delhi: Sage Publications Ltd.

Quinodoz, J-M. (2005). Reading Freud: A chronological exploration of Freud's writings. The new library of psychoanalysis Vol.6 (5):p. 64-66

Rothbauer, P. (2008). Triangulation. In Given, L. (Ed.), The SAGE Encyclopedia of Qualitative Research Methods. Sage Publications. pp. 892-894.

Santrock, J. W. \& Mitterer, J. O. (2006). Psychology (3rd Ed.) Toronto: McGraw-Hill Ryerson.

Santrock, J.W. (2007). A Topical Approach to Life-Span Development. New York: McGraw-Hill. 
Santrock, J.W. (2014). Life-Span Development. New York: McGraw-Hill Higher Education.

Scharf, M. \& Shulman, S. (2010). Adolescents' socio-emotional competence and parental representations of peer relationships in adolescence- A Paper presented at the Society for Research on Adolescence, Boston: Fireworks Press.

Stake, R.E. (2010). The point of triangulation. Journal of Nursing Scholarship,Vol. 33(3), 254-256. Retrieved from: http://www.rural health.utas.edu.au/gr/resources/docs/the-point-of-triangulation.pdf.on 11th December, 2013

Sturges, J.W. (2012). Use of therapist self-disclosure and self-involving statement. The Behavior Therapist 5 (35): 90-93.

Taylor, O. D. (2011). Adolescent depression as a contributing factor to the development of substance use disorders; Journal of Human Behavior in the Social Environment, Vol. 21, (60), 696-710.

Tharp-Taylor, S., Haviland, A. \& D'Amico,E. J. (2012). Victimization from mental and social disorders in early adolescence; Adolescent Behaviors, Vol. 34, (6-7), 561-567. 